\title{
Clinicopathological significance of prolactin receptor expression in colorectal carcinoma and corresponding metastases
}

Lars Harbaum ${ }^{1}$, Marion J Pollheimer ${ }^{1}$, Thomas Bauernhofer ${ }^{2}$, Peter Kornprat ${ }^{3}$, Richard A Lindtner ${ }^{1}$, Andrea Schlemmer ${ }^{4}$, Peter Rehak ${ }^{5}$ and Cord Langner ${ }^{1}$

\author{
${ }^{1}$ Institute of Pathology, Medical University of Graz, Graz, Austria; ${ }^{2}$ Division of Oncology, Department of \\ Internal Medicine, Medical University of Graz, Graz, Austria; ${ }^{3}$ Division of General Surgery, Department of \\ Surgery, Medical University of Graz, Graz, Austria; ${ }^{4}$ Institute for Medical Informatics, Statistics and \\ Documentation, Medical University of Graz, Graz, Austria and ${ }^{5}$ Department of Surgery, Research Unit for
} Biomedical Engineering and Computing, Medical University of Graz, Graz, Austria

\begin{abstract}
The role of human prolactin and its receptor, the prolactin receptor, in colorectal cancer is largely unknown. Our study aimed to assess the prevalence of prolactin receptor expression, its association with clinicopathological variables, as well as its prognostic value, comparing results of primary tissues with those of corresponding metastases. In all, 373 primary colorectal cancer and 171 corresponding metastases were evaluated for prolactin receptor expression by immunohistochemistry using a tissue microarray technique. Immunoreactivity was semiquantitatively scored as either focal ( $<10 \%$ of tumor cells positive), moderate (10-50\%), or extensive ( $>50 \%)$. Prolactin receptor expression was related to clinicopathological parameters as well as patient outcome. To substantiate our findings, prolactin receptor expression was additionally assessed in HT-29 and SW-480 colorectal cancer cell lines using western blot. Prolactin receptor expression was observed in 360 out of $373(97 \%)$ primary tumors, with 21 (6\%) cases showing focal, 55 (15\%) moderate, and 284 (76\%) extensive expression, respectively. Extensive prolactin receptor expression was significantly associated with tumor size $(P=0.002)$ and grade $(P<0.001)$ as well as histological subtype $(P<0.001)$. Somer's $D$ coefficients for concordance of primary tumors with corresponding lymph node and distant metastases were $D=0.719$ $(P<0.001)$ and $D=0.535(P=0.001)$, respectively. Extensive prolactin receptor expression was significantly associated with disease progression $(P=0.03)$ and cancer-specific survival $(P=0.04)$ in patients with highgrade cancers. In conclusion, prolactin receptor expression is common in colorectal cancer, with high concordance between primary tumors and corresponding metastases. In view of evolving targeted therapy concepts in colorectal cancer, widespread prolactin receptor expression may offer a therapeutic perspective in affected patients.
\end{abstract}

Modern Pathology (2010) 23, 961-971; doi:10.1038/modpathol.2010.83; published online 7 May 2010

Keywords: colorectal cancer; prolactin receptor; immunohistochemistry; cell line; survival; clinical significance; targeted therapy

Incidence of colorectal cancer ranks fourth in men (after lung, prostate, and stomach) and third in women (after breast and cervix uteri) accounting for about 1 million new cancer cases occurring every

Correspondence: Dr C Langner, MD, Institute of Pathology, Medical University of Graz, Auenbruggerplatz 25, A-8036 Graz, Austria.

E-mail: cord.langner@medunigraz.at

Received 8 February 2010; revised and accepted 9 April 2010; published online 7 May 2010 year worldwide with a similar number of cases in men and women for colon cancer and a male prevalence for rectal cancer. ${ }^{1}$ In the United States, colorectal cancer accounts for $\sim 10 \%$ of annual new cancer cases. About 150000 newly diagnosed cases and nearly 50000 deaths of the disease have been estimated for 2008. ${ }^{2}$ The overall lifetime risk in the United States for developing colorectal cancer is as high as $5.3 \% .^{3}$

Owing to advanced surgical techniques, new drugs, and multimodal therapy regimens, outcome 
and prognosis of colorectal cancer patients have markedly improved. Thus, chemotherapy based on 5-fluoruracil has decreased tumor recurrence in patients with nodal disease, whereas neoadjuvant chemoradiotherapy and total mesorectal excision have improved local control of rectal cancer. ${ }^{4-6}$ The introduction of new drugs, the so-called biologicals, which selectively target pathways implicated in tumor growth and development, such as epidermal growth factor receptor or vascular endothelial growth factor antagonists, has further improved outcome of affected patients. ${ }^{7-9}$

The role of human prolactin and its receptor, the prolactin receptor, in cancer has been analyzed for almost two decades. Prolactin receptor is expressed in various extrapituitary cells, including breast, liver, pancreas, and gastrointestinal tissues. In the latter, prolactin has been reported to act on water and electrolyte transport through the mucosa. ${ }^{10,11}$ Numerous studies have provided evidence implicating a pathogenetic role of prolactin in breast cancer. On prolactin binding, the receptor exerts mitogenic effects involving various intracellular signaling cascades, such as JAK-STAT, ras-MAPK, and SHCGrb pathways. ${ }^{12-14}$ Thus, prolactin and its receptor are promising therapeutic targets, wherein prolactin receptor antagonism appears to be the most promising interventional approach. ${ }^{15-17}$

The significance of prolactin and its receptor in colorectal cancer, however, is largely unknown. The expression of prolactin receptor in primary colorectal cancer has so far been analyzed by three studies, reporting significant higher level of prolactin receptor protein and mRNA expression in cancer tissue as compared with normal colorectal tissue. ${ }^{18-20}$ A systematic correlation of prolactin receptor expression with other tumor variables including analysis of prognostic impact is currently lacking.

Our study aimed to assess the prevalence of prolactin receptor expression, its association with other clinicopathological variables, as well as its prognostic value in a large cohort of colorectal cancer patients. Herein, we evaluated the expression profile of primary tumor tissues and corresponding metastases, which appears to be of particular interest regarding the possible therapeutic role of prolactin receptor antagonists in patients with metastatic disease. To substantiate our immunohistochemical findings in cancer tissues, we assessed prolactin receptor expression in HT-29 and SW-480 colorectal cancer cell lines with different methodological approaches.

\section{Materials and methods}

\section{Patient Selection}

During the period from January 1, 1984 to December 31,2005 , a total of 7909 colorectal cancers from 7564 patients (4095 males, 3469 females; ratio 1.2:1) were identified in the colorectal cancer database of the
Institute of Pathology, Medical University of Graz, Austria. Of these, $400(5 \%)$ patients were randomly sampled from January 1992 through December 2000 with the aim of obtaining identical adjuvant treatment modalities (see below) as well as at least 5 years' follow-up.

The following patients were excluded: (i) those who underwent endoscopic polypectomy for lowrisk $\mathrm{T} 1$ cancer because of missing data regarding nodal status; (ii) patients who underwent neoadjuvant chemotherapy because of presumptive treatment-related changes in $\mathrm{T}$ classification; (iii) patients with synchronous or metachronous secondary colorectal cancer; and (iv) patients with competitive invasive cancers originating from other sites if metastatic deposits were not assessed by histology.

In total, 381 specimens from 400 patients $(95 \%)$ were available for review pathology. There were 215 males $(56 \%)$ and 166 females $(44 \%)$ with a median age of 68.5 (range 27.6-93.1) years. Of these, 191 $(50 \%)$ were older than 70 years.

Tumors were located in the cecum in 49 patients $(13 \%)$, in the ascending colon in $27(7 \%)$, at the hepatic flexure in $18(5 \%)$, in the transverse colon in $13(3 \%)$, at the splenic flexure in $13(3 \%)$, in the descending colon in $15(4 \%)$, in the sigmoid colon in $82(22 \%)$, at the rectosigmoid junction in $15(4 \%)$, and in the rectum in 149 patients (39\%). Thus, 107 tumors $(28 \%)$ were found on the right side, 110 $(29 \%)$ on the left side, and $164(43 \%)$ in the rectum (including rectosigmoid junction).

Adjuvant chemotherapy was guided by AJCC/ UICC stage: stage I (T1 No M0 or T2 No Mo) and stage II (T3 No Mo or T4 No Mo) patients did not receive adjuvant therapy, whereas, stage III (any $\mathrm{T}$ N1 M0 or any $\mathrm{T}$ N2 M0) patients were given 5-fluorouracil/folinic acid according to the Mayo Clinic protocol. ${ }^{4}$

Follow-up included laboratory testing (including blood count, liver enzymes, and tumor markers (CEA and CA19-9) at 3-month intervals; after 3 years the interval was extended to 6 months. Chest X-ray and abdominal ultrasound were performed at 6-month intervals; after 3 years the interval was extended to 12 months. Patients with rectal cancer underwent computerized tomography every 12 months.

Institutional review board approval was received from the Ethic's Committee of the Medical University of Graz, Austria.

\section{Histopathology}

Slide review was independently performed by two investigators (MP and CL). Discrepancies were resolved by simultaneous re-examination of the slides by both investigators using a double-headed microscope. T and $\mathrm{N}$ classifications were adjusted to the 2002 edition of the AJCC/UICC TNM system. ${ }^{21}$ 
Histological tumor type and tumor grades were assessed according to the WHO classification. ${ }^{22}$

\section{Immunohistochemistry}

Using a tissue microarray technique provided the immunohistochemical evaluation. The details of this technique have been described earlier. ${ }^{23}$ Briefly, tissue microarrays were constructed using a manual tissue-arraying instrument (Beecher, Silver Spring, MD, USA). To account for tumor heterogeneity, between 3 and 14 (mean 5.03, median 5) cylindrical core biopsies, $0.6 \mathrm{~mm}$ in diameter, were taken from different sites of each tumor and arrayed in recipient paraffin tissue microarray block. Corresponding lymph node and distant metastases were included in 143 and 42 cases, respectively. In all, $4 \mu \mathrm{m}$ tissue microarrays sections were stained using an automated staining system (BenchMark ${ }^{\mathrm{TM}}$ Ventana Medical Systems, SA, Illkirch, Cedex, France). Enzymatic digestion was performed using Protease Type 1 (concentration 0.5 enzyme unit/ml, Catalog No. 760-2018, Ventana) for $32 \mathrm{~min}$. The primary prolactin receptor antibody (Ab-1, Clone B6.2; Thermo Fisher Scientific, Fremont, CA, USA) was applied at 1:400 dilution, and the reaction was visualized using the ultraVIEW Universal DAB Detection kit ${ }^{\mathrm{TM}}$ (Catalog No. 760-500, Ventana).

Immunoreactivity was independently assessed by two investigators (LH and CL), who were blinded to clinicopathologic data, using a semiquantitative scoring system. Discrepancies were resolved by simultaneous re-examination of the slides by both investigators using a double-headed microscope.

A distinct membranous and/or granular cytoplasmic staining was considered positive, and immunoreactivity was semiquantitatively categorized as 'focal' ( $<10 \%$ of tumor cells positive), 'moderate' $(10-50 \%)$, or 'extensive' (>50\%). Each tumor was scored assessing the average positivity of the core biopsies. Slides of breast cancer, known to express prolactin receptor, served as positive control. Negative controls included omission of the primary antibody and incubation with Ventana Antibody Diluent (Catalog No. 251-018).

\section{Cell Lines}

Commercially available colon cancer cell lines HT29 and SW-480 and the breast cancer cell line T47D were used for experiments. HT-29 and T47D were purchased from American Type Culture Collection (Manassas, VA, USA, http://www.atcc.org; HT-29 Catalog No. HTB-38, T47D Catalog No. HTB-133) and SW-480 from DSMZ (Deutsche Sammlung von Mikroorganismen und Zellkulturen $\mathrm{GmbH}$, Braunschweig, Germany, http://www.dsmz.de; Catalog No. ACC 313). Cells were cultivated according to the manufacturer's instructions. The media, the fetal bovine serum 'Gold' EU approved (FBS 'Gold') as well as the Penstrep were obtained from PAA Laboratories (Pasching, Austria). Twenty-four hours before collection, cells were cultivated in appropriate media supplemented with charcoal stripped 10\% fetal bovine serum (Bio Products, Grossmugl, Austria) to avoid blocking of prolactin receptor on cell surface by prolactin contained in unmanipulated fetal bovine serum. For prolactin receptor immunostaining, cells were collected and cell pellets were embedded in bacto agar (Becton Dickinson and Company, Franklin Lakes, NJ, USA), fixed in formalin, and embedded in paraffin following standard procedures as published earlier. ${ }^{24}$

\section{Western Blot}

Cell lines were collected and lysed using RIPA Buffer (Radioimmunoprecipitation Buffer, formulation according to Abcam, Cambridge, MA, USA) supplemented with $1 \mathrm{mM}$ phenylmethanesulfonyl fluoride, $10 \mathrm{mM}$ DTT (both purchased from SigmaAldrich, St Louis, MO, USA) and $1 \times$ Protease Inhibitor Cocktail (Invitrogen Leek, the Netherlands). The amount of extracted protein was detected with $660 \mathrm{~nm}$ Protein Assay kit (Thermo Fisher Scientific). SDS-page electrophoresis was performed using $10 \%$ polyacrylamide dissolving gels with $2.5-20 \mu \mathrm{g}$ protein per lane. Proteins were transferred onto a nitrocellulose membrane (Applichem, Darmstadt, Germany). After the membrane was blocked with $5 \%$ skim milk powder in TBS-T (Abcam), the primary prolactin receptor antibody (Ab-1, Clone B6.2; Thermo Fisher Scientific) was incubated at a dilution of 1:1500 in $0.5 \%$ skim milk powder TBS-T (at $4^{\circ} \mathrm{C}$, overnight). Anti- $\beta$-actin (Sigma-Aldrich) was incubated at 1:20000 under the same conditions as described above and served as a positive loading control. As an isotype control universal mouse negative control IgG (Dako, Glostrup, Denmark) was diluted at 1:100. Next, the membrane was washed and incubated with the secondary antibody (polyclonal rabbit anti-mouse immunoglobulins/HRP, Dako) at a dilution of 1:1000 (at room temperature, for $2 \mathrm{~h}$ ). Visualization of X-ray films was performed using SuperSignal West Femto Chemiluminescent Substrate (Thermo Scientific, Rockford, IL, USA) and Photo developer Curix 60 (Wiroma, Niederscherli, Switzerland) according to the manufacturer's instructions. T47D cell line was used as positive control and supernatant of the cell cultures as well as the cell culture media served as negative controls. The molecular weight of the protein bands was analyzed using SeeBlue Plus2 Pre-Stained Standard (Invitrogen).

\section{Statistical Analysis}

Progressive disease was defined as either local recurrence (any detectable local disease at followup, occurring either alone or in conjunction with 
generalized recurrence) or systemic recurrence (as any detectable disease at follow-up, except local disease).

Associations between prolactin receptor expression and other tumor parameters, such as $\mathrm{T}$ classification, $\mathrm{N}$ classification, tumor differentiation, angioinvasion, and AJCC/UICC stage, were analyzed using $\chi^{2}$ or Fisher's exact test, respectively. Disease-free (progression-free) and cancer-specific survival were assessed with the Kaplan-Meier method and compared by the log-rank test. For multivariate testing, Cox's proportional hazards regression model was used. All reported $P$-values were two-sided with significance at $P<0.05$.

To assess concordance of immunostaining results between primary and corresponding lymph node and/or distant metastases the Somer's $D$ rank-order correlation coefficient was used.

All statistical calculations were performed using NCSS (Hintze, 2007; NCSS, LLC, Kaysville, UT, USA; www.ncss.com) and StatXact (Cytel Software Corporation, Cambridge, MA, USA).

\section{Results}

\section{Histopathology}

The tumor distribution according to the $\mathrm{T}$ and $\mathrm{N}$ classifications, AJCC/UICC stage, and tumor grade is shown in Table 1. The majority of tumors extended beyond the bowel wall. Positive lymph nodes were detected in more than $40 \%$ of cases. Tumor grades were G1 in 121 (32\%), G2 in 138 (36\%), G3 in 99 (26\%), and G4 in $23(6 \%)$ cases, respectively.

Overall, 316 (83\%) tumors were adenocarcinomas, $45(12 \%)$ mucinous adenocarcinomas, and 13 (3\%) undifferentiated carcinomas. Seven cases presented rare histological subtypes, including three signet-ring cell, two medullary, one adenosquamous, and one amphicrine carcinoma, respectively. Lymph vessel and blood vessel invasion were detected in 126 (33\%) and 87 (23\%) cases.

\section{Immunohistochemistry}

Prolactin receptor expression was observed in 360/ $373(97 \%)$ evaluable primary tumors, with $21(6 \%)$

Table 1 Patient cohort: distribution of $\mathrm{T}$ and $\mathrm{N}$ classifications, AJCC/UICC stage, and tumor grade

\begin{tabular}{lrrrrrrr}
\hline$T$ & $\mathrm{n}(\%)$ & $\mathrm{N}$ & $\mathrm{n}(\%)$ & Stage & $\mathrm{n}(\%)$ & $G$ & $\mathrm{n}(\%)$ \\
\hline T1 & $28(7)$ & N0 & $213(56)$ & I & $81(21)$ & 1 & $121(32)$ \\
T2 & $70(18)$ & N1 & $83(22)$ & IIA & $110(29)$ & 2 & $138(36)$ \\
T3 & $218(57)$ & N2 & $85(22)$ & IIB & $10(3)$ & 3 & $99(26)$ \\
T4 & $65(17)$ & & & IIIA & $5(1)$ & 4 & $23(6)$ \\
& & & & IIIB & $61(16)$ & & \\
& & & IIIC & $60(16)$ & & \\
& & & IV & $54(14)$ & \\
\hline
\end{tabular}

cases showing focal, 55 (15\%) moderate, and 284 $(76 \%)$ extensive expression, respectively. Staining was homogenous, mainly cytoplasmic, but with membranous accentuation (Figure 1a-c). Adjacent non-neoplastic epithelial cells showed comparatively weak immunoreactivity with staining accentuation at the mucosal surface (Figure 1d).

Extensive prolactin receptor expression in primary tumors was significantly associated with histological subtype, tumor size, and grade (Table 2). Thus, extensive prolactin receptor expression was observed in 205/254 (81\%) low-grade (G1/ G2), yet in only 79/119 (66\%) high-grade (G3/G4) cancers $(P=0.004)$. This finding, however, is most probably related to the fact, that extensive prolactin receptor expression was comparably low in mucinous adenocarcinomas, which, according to the current WHO classification, ${ }^{22}$ are by convention considered poorly differentiated (G3). Thus, restricting analysis to classical (non-mucinous) adenocarcinomas, extensive prolactin receptor expression was observed in similar amounts in low-grade (G1/ G2: $205 / 254$ or $81 \%$ ) and high-grade (G3/G4: 45/58 or $78 \%)$ cancers $(P=0.59)$. Anyhow, it should be noted that only about $50 \%$ of undifferentiated tumors showed extensive prolactin receptor expression. Sample size, however, was small (Table 2).

Immunoreactivity of metastatic tissues matched well with that of corresponding primary tumors. If primary tumors were negative for prolactin receptor, metastatic sites similarly lacked immunolabeling. If primary tumors, however, showed extensive prolactin receptor expression, 96/104 (92\%) corresponding nodal and 28/32 (86\%) corresponding distant metastases also showed high expression (Table 3). Somer's $D$ coefficients for concordance of primary tumors with corresponding lymph node and distant metastases were $D=0.719(P<0.001)$ and $D=0.535$ $(P=0.001)$, respectively.

\section{Survival Analysis}

Follow-up data were available for 350 (92\%) patients. Median follow-up was 45 months (mean 56 , range 0-180). At the time of last follow-up, 173 $(49 \%)$ patients showed no evidence of disease. Progressive disease was observed in 141 (40\%) patients including $117(33 \%)$ patients who died from cancer and $11(3 \%)$ patients who are currently alive with metastatic disease. Median time to progression was 7 months (mean 15, range 0-88). In all, 49 (14\%) patients died from causes not related to colorectal cancer.

Disease progression occurred in 24/78 (31\%) patients with tumors either lacking prolactin receptor expression or showing only focal/moderate expression and 116/264 (44\%) patients with tumors showing extensive prolactin receptor expression $(P=0.08$, log-rank test; Figure 2a). Actuarial 5-year progression-free (disease-free) survival rates for patients with tumors either lacking prolactin 

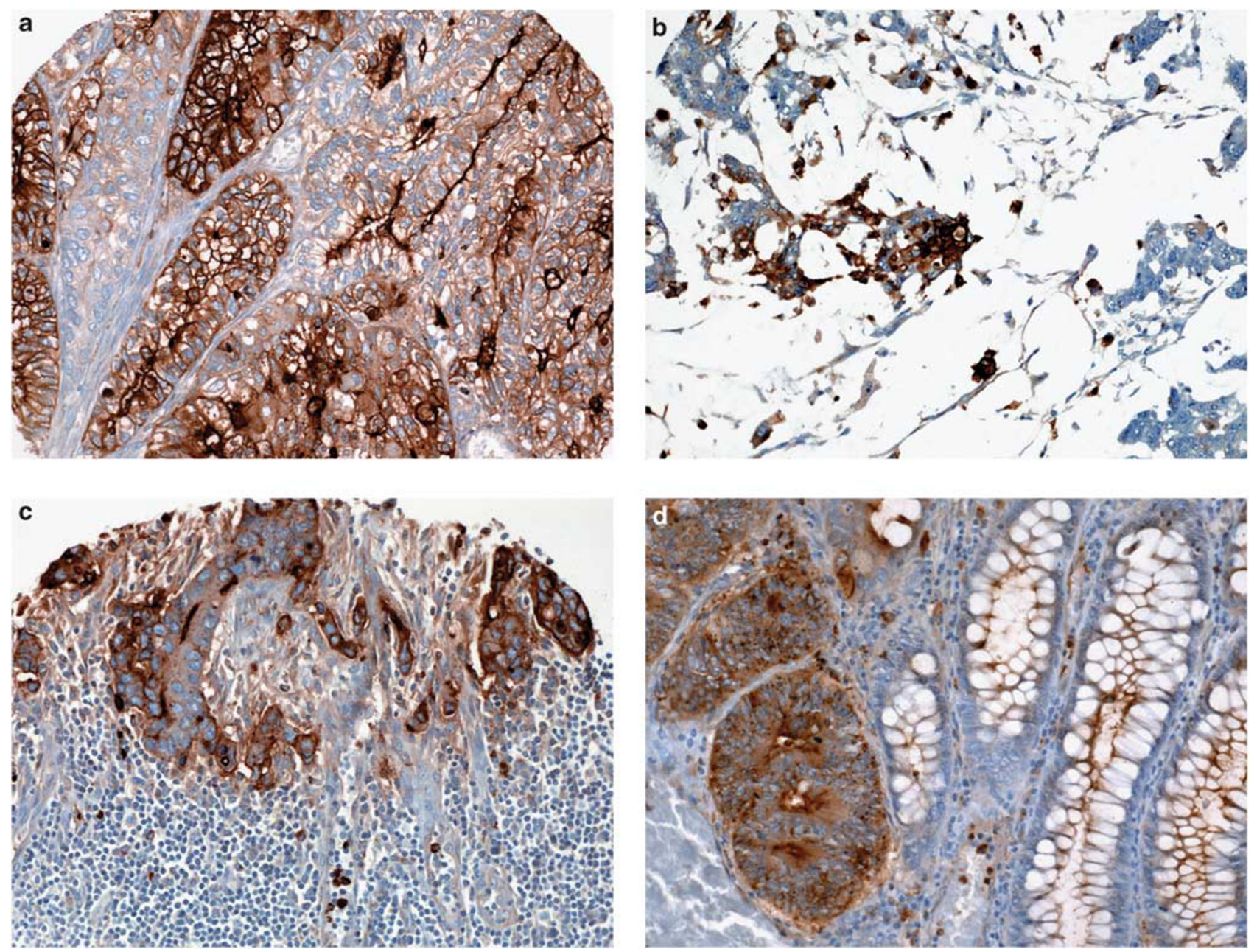

Figure 1 Expression of prolactin receptor in classical (non-mucinous) colorectal adenocarcinoma (a, original $\times 100$ ), in mucinous colorectal adenocarcinoma $(\mathbf{b}$, original $\times 100)$, and in lymph node metastasis of colorectal cancer $(\mathbf{c}$, original $\times 100)$; note comparably weak prolactin receptor expression in adjacent non-neoplastic mucosa $(\mathbf{d}$, original $\times 100)$.

receptor expression or showing only focal/moderate expression and patients with tumors with extensive prolactin receptor expression were 68 and $56 \%$, respectively.

In addition, $19 / 78(24 \%)$ patients with tumors either lacking prolactin receptor expression or showing only focal/moderate expression and 98/ $264(37 \%)$ patients with tumors showing extensive prolactin receptor died of disease $(P=0.08$, log-rank test; Figure 2b). Actuarial 5-year cancer-specific survival rates for patients with tumors either lacking prolactin receptor expression or showing only focal/ moderate expression and patients with tumors with extensive prolactin receptor expression were 73 and $62 \%$, respectively.

Regarding only patients with high-grade (G3/G4) tumors, $43 / 73$ (59\%) patients with tumors showing extensive prolactin receptor expression experienced disease progression compared with 11/33 (33\%) patients with tumors either lacking prolactin receptor expression or showing only focal/moderate expression $(P=0.03$, log-rank test; Figure 3a). Similarly, 39/73 (53\%) patients with tumors with extensive prolactin receptor expression died of disease in this group compared with 9/33 (27\%) patients with tumors either lacking prolactin receptor expression or showing only focal/moderate expression ( $P=0.04$, log-rank test; Figure $3 \mathrm{~b})$.

In Cox's proportional hazards regression models restricted to patients with high-grade (G3/G4) tumors presence of lymph node metastasis proved to be the only independent predictor of both progression-free and cancer-specific survival. Patients with tumors showing extensive prolactin receptor expression were more likely to experience disease progression (hazard ratio 1.62, 95\% confidence interval $0.77-3.40$ ) or to die of disease (hazard ratio $2.01,95 \%$ confidence interval 0.89 4.53), but differences were not statistically significant (Table 4).

To appraise the possible impact of histological subtype on analysis, we recalculated data in classical (non-mucinous) adenocarcinomas and and mucinous adenocarcinomas separately.

In the group of classical adenocarcinomas for which follow-up data were available $(n=289)$ 
Table 2 Association of prolactin receptor expression with different tumor characteristics

\begin{tabular}{|c|c|c|c|}
\hline & \multicolumn{2}{|c|}{ Prolactin receptor immunoreactivity } & \multirow[t]{2}{*}{ P-value } \\
\hline & Positive (\%) & Extensive expression (\%) & \\
\hline \multicolumn{4}{|l|}{ T classification } \\
\hline $\mathrm{T} 1$ & $24 / 26(92)$ & $20 / 26(77)$ & 0.15 \\
\hline $\mathrm{T} 2$ & 66/69 (96) & 48/69 (70) & \\
\hline T3 & $206 / 213(97)$ & $160 / 213(75)$ & \\
\hline $\mathrm{T} 4$ & 64/65 (98) & $56 / 65(86)$ & \\
\hline \multicolumn{4}{|l|}{$N$ classification } \\
\hline No & 199/208 (96) & $152 / 208(73)$ & 0.29 \\
\hline N1 & 80/82 (98) & 66/82 (80) & \\
\hline $\mathrm{N} 2$ & $81 / 83(98)$ & $66 / 83(75)$ & \\
\hline \multicolumn{4}{|l|}{ AJCC/ UICC Stage } \\
\hline I & $75 / 80(88)$ & $55 / 80(69)$ & 0.30 \\
\hline II & $112 / 116(97)$ & $88 / 116(76)$ & \\
\hline III & 121/124 (98) & 99/124 (80) & \\
\hline IV & $52 / 53(98)$ & $42 / 53(79)$ & \\
\hline \multicolumn{4}{|l|}{ Grade } \\
\hline G1 & 114/118 (97) & $87 / 118(74)$ & $<0.001$ \\
\hline $\mathrm{G} 2$ & 135/136 (99) & $118 / 136(87)$ & \\
\hline G3 & 90/97 (93) & 7/97 (69) & \\
\hline G4 & $21 / 22(95)$ & $12 / 22(55)$ & \\
\hline \multicolumn{4}{|l|}{ Histology } \\
\hline Adenocarcinoma & $304 / 312(97)$ & $250 / 312(80)$ & $<0.001$ \\
\hline Mucinous Ca. & $37 / 42(88)$ & $23 / 42(55)$ & \\
\hline Undifferentiated Ca. & $12 / 12(100)$ & $7 / 12(58)$ & \\
\hline Other Ca. & $7 / 7(100)$ & $4 / 7(57)$ & \\
\hline \multicolumn{4}{|l|}{ Tumor size } \\
\hline$\leq 4.5 \mathrm{~cm}$ & 191/194 (98) & 161/194 (83) & 0.002 \\
\hline$>4.5 \mathrm{~cm}$ & 148/157 (94) & 108/157 (69) & \\
\hline \multicolumn{4}{|l|}{ Lymphatic invasion } \\
\hline LO & $241 / 250$ (96) & $190 / 250(76)$ & 1 \\
\hline L1 & 119/123 (97) & $94 / 123(76)$ & \\
\hline \multicolumn{4}{|l|}{ Venous invasion } \\
\hline Vo & $277 / 286$ (97) & $216 / 286(76)$ & 0.67 \\
\hline V1 & 83/87 (95) & $68 / 87$ (78) & \\
\hline \multicolumn{4}{|l|}{ Age } \\
\hline$\leq 70$ & 179/184 (97) & 139/184 (76) & 0.81 \\
\hline$>70$ & 181/189 (96) & 145/189 (77) & \\
\hline \multicolumn{4}{|l|}{ Gender } \\
\hline Female & 161/164 (98) & $123 / 164(75)$ & 0.71 \\
\hline Male & 199/209 (95) & $161 / 209(77)$ & \\
\hline
\end{tabular}

99/233 (42\%) patients with tumors showing extensive prolactin receptor expression experienced disease progression compared with 17/56 (30\%) patients with tumors either lacking prolactin receptor expression or showing only focal/moderate expression $(P=0.19$, log-rank test $)$. In addition, $84 / 233(36 \%)$ patients with tumors with extensive prolactin receptor expression died of disease compared with 14/56 (25\%) patients with tumors either lacking prolactin receptor expression or showing only focal/moderate expression $(P=0.23$, log-rank test).

In the much smaller group of mucinous adenocarcinomas $(n=39)$, data were nearly significant, thus indicating stronger prognostic value of prolactin receptor immunostaining in this distinct type of cancer. In all, $12 / 23(52 \%)$ patients with tumors showing extensive prolactin receptor expression experienced disease progression compared with 4/16 (25\%) patients with tumors either lacking prolactin receptor expression or showing only focal/moderate expression $(P=0.06$, log-rank test; Figure 4a). Similarly, 10/23 (43\%) patients with tumors with extensive prolactin receptor expression died of disease compared with 3/16 (19\%) patients with tumors either lacking prolactin receptor expression or showing only focal/moderate expression $(P=0.08$, log-rank test; Figure $4 b)$. 
Table 3 Concordance of prolactin receptor expression in primary and corresponding metastatic tumor tissues $(n=151$ primary tumors with lymph node $(n=132)$ and/or distant $(n=39)$ metastases $)$

\begin{tabular}{llcl}
\hline Primary tumor & \multicolumn{1}{c}{ Lymph node metastasis $(\%)$} & Distant metastasis (\%) \\
\hline T negative & Negative & $4 / 4(100)$ & Negative \\
$4 / 151(3 \%)$ & Focal & - & Focal \\
& Moderate & - & Moderate \\
& Extensive & - & Extensive \\
T focal & Negative & - & Negative \\
$9 / 151(6 \%)$ & Focal & $3 / 6(50)$ & Focal \\
& Moderate & $1 / 6(17)$ & Moderate \\
& Extensive & $2 / 6(33)$ & Extensive \\
T moderate & Negative & - & Negative \\
$19 / 151(13 \%)$ & Focal & - & Focal \\
& Moderate & $15 / 18(83)$ & Moderate \\
T extensive & Extensive & $3 / 18(17)$ & Extensive \\
$119 / 151(79 \%)$ & Negative & - & Negative \\
& Focal & $1 / 104(1)$ & Focal \\
& Moderate & $7 / 104(7)$ & Moderate \\
& Extensive & $96 / 104(92)$ & Extensive
\end{tabular}
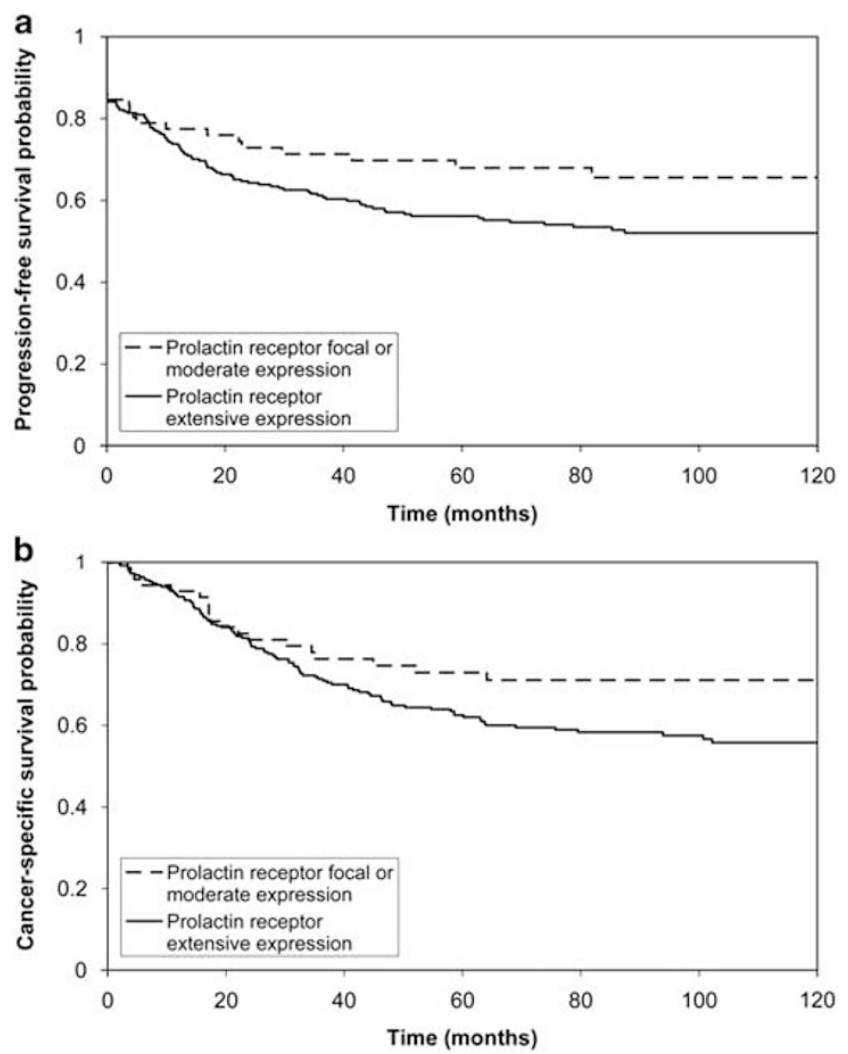

Figure 2 Progression-free (a, $P=0.08$, log-rank test) and cancerspecific (b, $P=0.08$, log-rank test) survival in patients with colorectal carcinoma related to prolactin receptor expression (extensive prolactin receptor expression vs focal/moderate prolactin receptor expression).

\section{Cell Lines}

To substantiate the specificity of prolactin receptor staining results we thought to examine prolactin receptor protein expression in the colon cancer cell lines HT-29 and SW-480 using immunohistochemistry as well as western blotting. Intensive prolactin
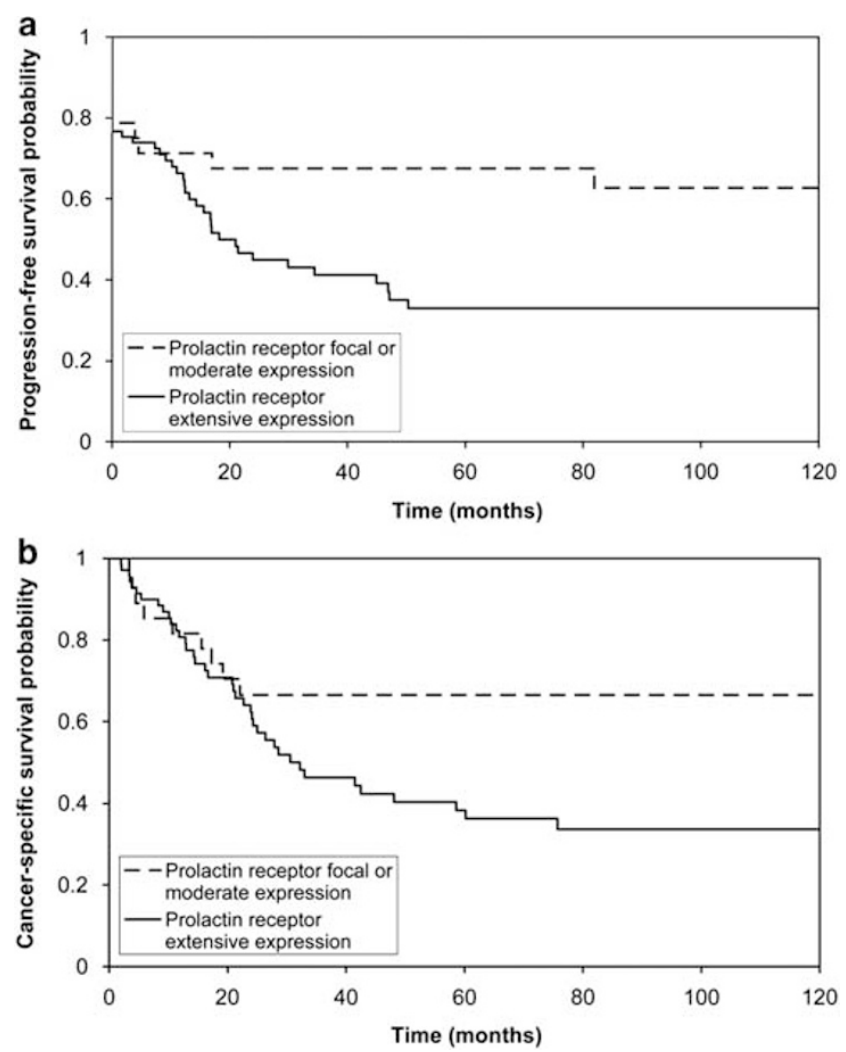

Figure 3 Progression-free (a, $P=0.03$, log-rank test) and cancerspecific (b, $P=0.04$, log-rank test) survival in patients with highgrade (G3/G4) colorectal carcinoma related to prolactin receptor expression (extensive prolactin receptor expression vs focal/ moderate prolactin receptor expression).

receptor staining was observed in HT-29 cells (and in T47D breast cancer cells, serving as positive control), whereas SW-480 cells showed weak to moderate immunolabeling of single cancer cells (Figure 5a-c). In accordance, western blotting showed a prominent band at $78 \mathrm{kDa}$ corresponding to the prolactin receptor protein in the lysate of 
Table 4 Cox's proportional hazards regression model of patients with high-grade (G3/G4) colorectal cancer with respect to progression-free and cancer-specific survival

\begin{tabular}{|c|c|c|c|c|c|c|}
\hline & \multicolumn{3}{|c|}{ Progression-free survival } & \multicolumn{3}{|c|}{ Cancer-specific survival } \\
\hline & Hazard Ratio & $95 \% C I$ & $\mathrm{P}$-value & Hazard Ratio & $95 \% C I$ & $\mathrm{P}$-value \\
\hline Age $(>70)$ & 1.14 & $0.65-2.01$ & 0.64 & 1.29 & $0.7-2.37$ & 0.41 \\
\hline Male gender & 0.98 & $0.56-1.73$ & 0.95 & 1.30 & $0.70-2.40$ & 0.41 \\
\hline $\mathrm{T}$ classification $>2$ & 2.35 & $0.56-9.96$ & 0.25 & 2.57 & $0.61-10.79$ & 0.20 \\
\hline Tumor size $>4.5 \mathrm{~cm}$ & 1.56 & $0.86-2.86$ & 0.15 & 1.74 & $0.92-3.29$ & 0.09 \\
\hline Nodal disease (UICC III) & 4.28 & $2.06-8.86$ & 0.0001 & 4.10 & $1.92-8.74$ & 0.0003 \\
\hline $\begin{array}{l}\text { Extensive prolactin } \\
\text { receptor expression }\end{array}$ & 1.62 & $0.77-3.40$ & 0.21 & 2.01 & $0.89-4.53$ & 0.09 \\
\hline
\end{tabular}
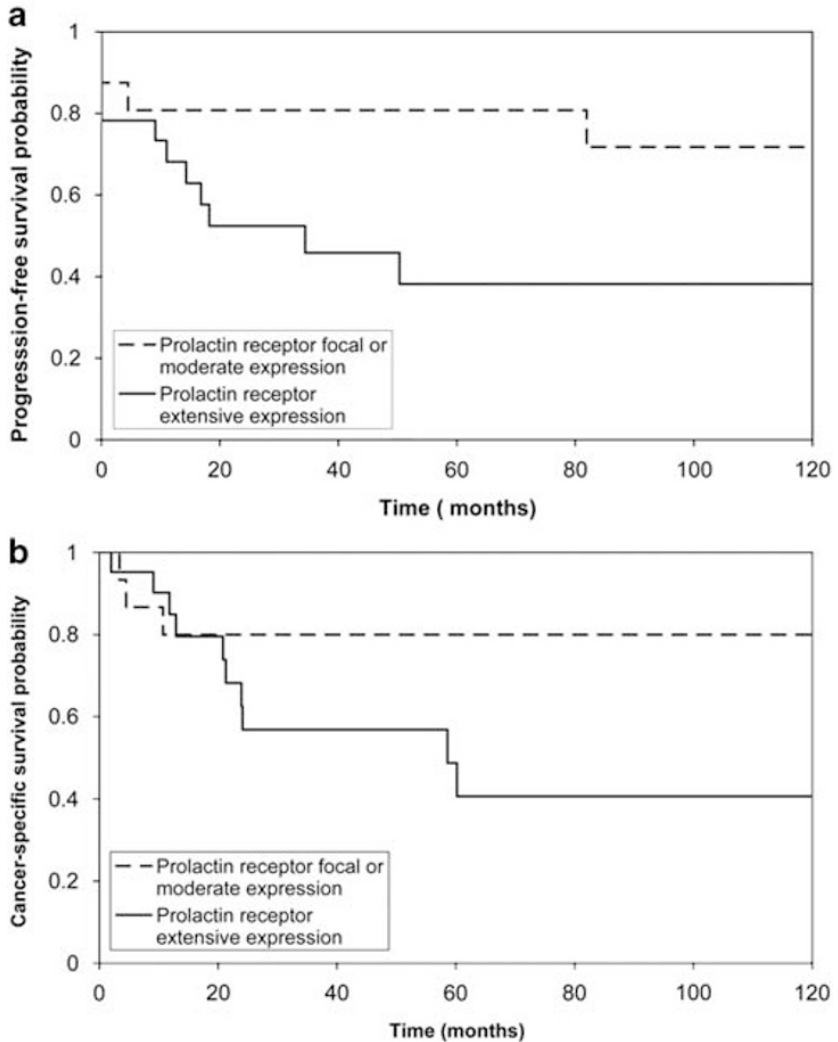

Figure 4 Progression-free (a, $P=0.06$, log-rank test) and cancerspecific (b, $P=0.08$, log-rank test) survival in patients with mucinous colorectal adenocarcinoma related to prolactin receptor expression (extensive prolactin receptor expression vs focal/ moderate prolactin receptor expression).

HT-29 cells, whereas no band was detected in the lysate of SW-480 cells (Figure 5d-e). Although we increased the amount of protein of SW-480 cell lysate by $1^{\log }$ compared with HT-29 cell lysate we were not able to detect a signal suggesting a very low expression of prolactin receptor corresponding to findings in immunohistochemistry.

\section{Discussion}

The prolactin hormone, synthesized by lactotrophic cells of the anterior pituitary gland, has been attributed with numerous biological effects, including functions linked to reproduction, metabolism, water and electrolyte balance, growth and development, as well as immunoregulation. ${ }^{11}$ However, prolactin exerts its effects not only through an endocrine but also through autocrine and/or paracrine activity. ${ }^{25}$

The human prolactin receptor is a single-pass transmembrane, non-tyrosine kinase receptor belonging to the class 1 cytokine receptor superfamily. The gene encoding the receptor is localized on chromosome 5p13-14 and contains at least 10 exons. Alternative splicing of those yields multiple isoforms, which are differing in length and composition of their cytoplasmatic component and are referred to as short, intermediate, or long prolactin receptor depending on their size. ${ }^{11}$

Prolactin binding leads to homodimerization of two receptor molecules, thereby activating different signal transduction cascades, which ultimately lead to cell proliferation. Data obtained from breast cancer cell lines and in vivo models show that intracellular signaling involves phosphorylation of cytoplasmatic transcription factors, eg, signal transducer and activator of transcription (STAT) 1, STAT3, or STAT5, through recruited kinases, eg, janus-kinase JAK2, or activation of the ras-MAPK pathway. ${ }^{12,14}$

According to our data, prolactin receptor is widely expressed in colorectal cancer. Immunoreactivity was significantly associated with tumor differentiation and histological subtype, which is reported in this study for the first time. Patients with extensive prolactin receptor expression were more likely to experience disease progression and cancerrelated death. This effect was pronounced in highgrade tumors and in mucinous adenocarcinomas. Specificity of immunohistochemical staining was endorsed by cell line experiments. Interestingly, the colon cancer cell lines HT-29 and SW-480 used in our study differentially expressed prolactin receptor. SW-480 cell line showed weak to no expression of prolactin receptor whereas HT-29 cell line showed a high expression of prolactin receptor. The difference in prolactin receptor expression goes parallel to different in vivo behavior of HT-29 and SW-480 cells, with high expression levels in cells exhibiting an aggressive phenotype. Thus, HT-29 

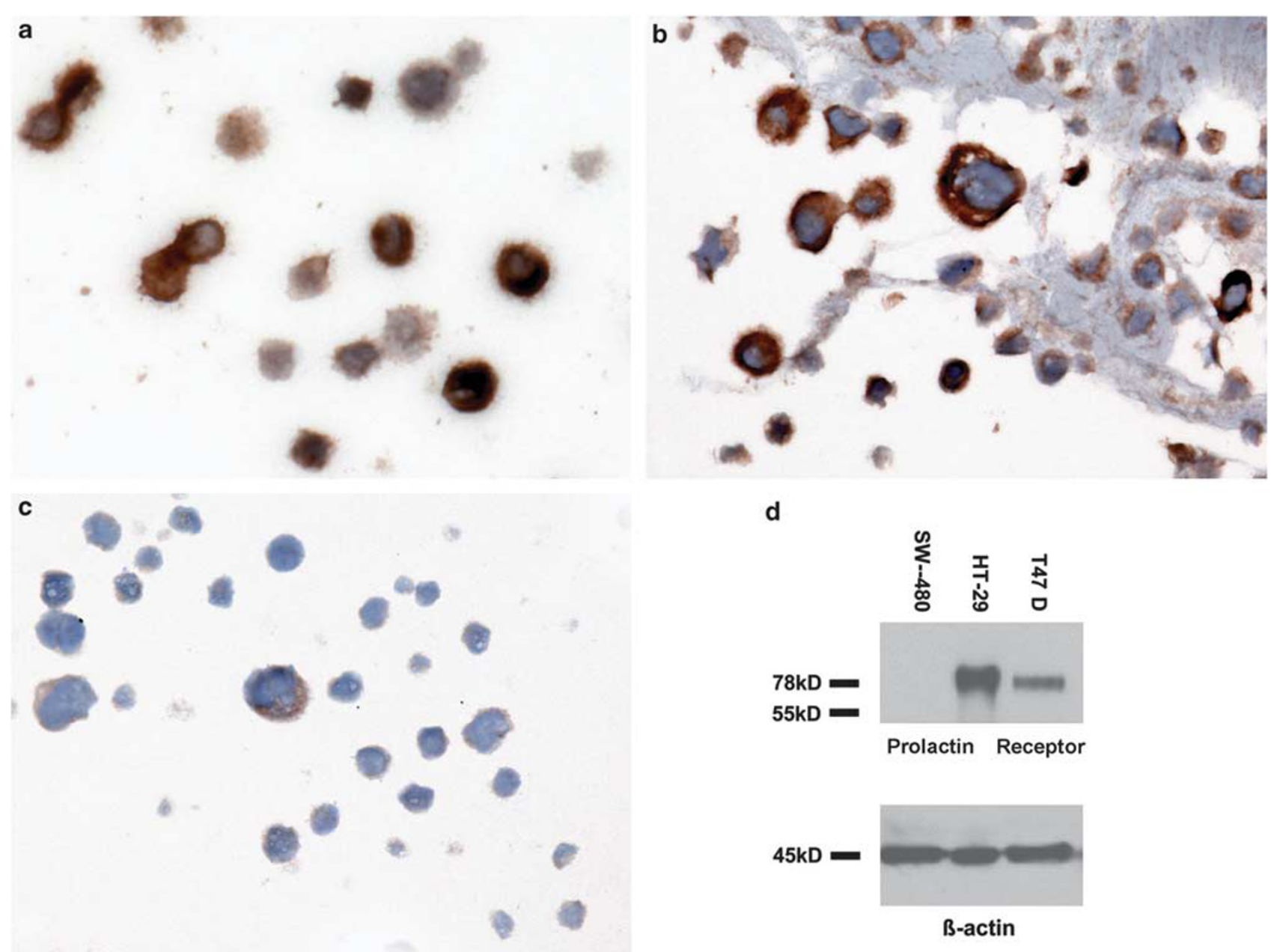

d
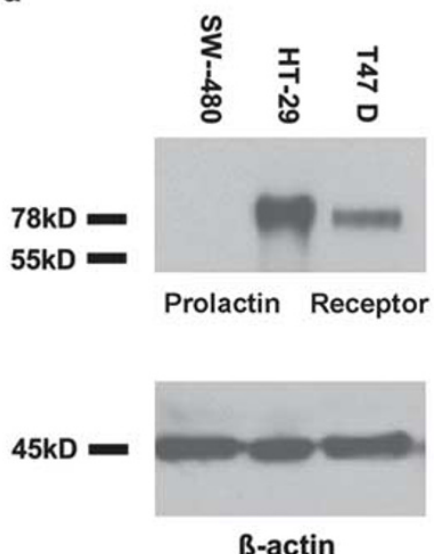

Figure 5 Intensive prolactin receptor staining in HT-29 colon cancer cells (a) and in T47D breast cancer cells serving as positive control (b). Weak staining of single cells in SW-480 colon cancer cells (c). Western blotting shows a prominent band at $80 \mathrm{kDa}$ corresponding to the prolactin receptor protein in the lysate of HT-29 cells, whereas no band was detected in the lysate of SW-480 cells. The expression of prolactin receptor in HT-29 cells was 10-fold compared to T47D cells (d). Anti- $\beta$-actin served as a positive loading control. Please note that the protein concentration of SW-480 and T47D cell lysates was $20 \mu \mathrm{g}$, and that of HT-29 was $2.5 \mu \mathrm{g}$, respectively, because of the $1^{\log }$ difference in prolactin receptor expression. The western blot presented is representative for five experiments.

cells have been reported to show local invasion and marked metastatic capacity after subcutaneous and intracaecal xenografting in nude mice, whereas SW480 cells showed solid growth without invasion in the bowel wall or the development of metastases. ${ }^{26}$ This pair of cell lines may consequently be used as a model system for further research of the role of prolactin in the biology of colon cancer.

To the best of our knowledge, only three studies have so far addressed the topic of prolactin receptor expression in colorectal cancer. ${ }^{18-20}$ The first study assessed prolactin receptor protein by radioligand assay using ${ }^{125} \mathrm{I}-\mathrm{hGH}$. Tumor specimens of 71 male patients were analyzed and prolactin receptor was found to be positive in $36(51 \%)$ patients. ${ }^{18}$ No associations with clinicopathological variables were noted and prolactin receptor protein content was independent from outcome. In a second study, the same group of authors noted prolactin receptor immunoreactivity in 26 out of 56 (46\%) tumors. ${ }^{19}$ The authors used a monoclonal mouse anti-human prolactin receptor antibody different from the one used in our study, which may have accounted for the low prevalence of prolactin receptor expression. Data were not correlated with follow-up in this analysis.

In the third study by Otte et $a l^{20}$ the long transcript of prolactin receptor mRNA was detected in 45 out of $48(94 \%)$ of cancer specimens as well as in 22 out of $23(96 \%)$ normal colonic tissues. Expression in cancer tissue did not differ significantly between tumors of different grades. mRNA encoding for the short form of prolactin receptor was not found in any samples analyzed. In addition, prolactin receptor protein was detected by western blotting in 39 out of $45(87 \%)$ cancer specimens and in 17 out of 22 $(77 \%)$ normal tissues. Similar to our data, the prolactin receptor was detected on the membrane and in the cytoplasm of epithelial cells in normal and cancer tissue. Data regarding the percentage of tumors stained, however, were not provided and follow-up information was not given. 
Remarkably, in all the three studies the patient cohorts consisted only of male patients and/or postmenopausal women. Thus, our study is the first to analyze an unselected cohort of patients, including a random sample of female and male patients of all ages. It is known that prolactin secretion is greatly affected by the menstrual cycle. ${ }^{11}$ It is, however, largely unknown whether prolactin receptor expression, particularly in the gastrointestinal mucosa, varies accordingly in female patients. Of note, we did not find an association between prolactin receptor expression and gender. Moreover, there was no difference in immunoreactivity among pre- and postmenopausal women (data not shown).

Data in the literature regarding the ectopic expression of prolactin in colorectal cancer are controversial, with prevalence rates ranging from 0 to $77 \% .^{20,27-32}$ Of note, compared with normal colorectal tissue, cancer tissues show a significantly higher rate of co-expression of prolactin and its receptor. Thus, in addition to systemic effects, prolactin presumably acts through an auto-/paracrine loop in promoting cell proliferation, as shown in colorectal cancer cell lines (CaCO-2, HT-29, and LoVo cells). ${ }^{20,25}$

As pointed out above, prolactin and its receptor are promising anti-cancer targets, wherein prolactin receptor antagonism appears to be the most promising interventional approach. ${ }^{15-17,33}$ First, results showing a beneficial effect of prolactin/prolactin receptor-targeted therapy in breast cancer have been reported from both in vitro and in vivo models using either pure prolactin receptor antagonists, such as $\Delta 1-9-G 129 R-h P R L$ or $\Delta 1-14-G 129 R-h P R L$, or fusion peptides between a prolactin receptor antagonist and potential anti-tumor peptides, such as G129RhPRL-IL2, G129R-hPRL-endostatin, or G129R-hPRLPE40-KDEL. ${ }^{12,34-36}$ However, these drugs are in early stages of development and application, and difficulties regarding stability and binding affinity of prolactin receptor antagonist must be overcome before entering the clinic. ${ }^{33}$ Nevertheless, a single clinical therapy trial using the anti-prolactinemic drug cabergoline combined with docetaxel in woman with metastatic breast cancer and concomitant hyperprolactinemia showed that tumor regression rate was significantly higher in patients treated with cabergoline than in those who received docetaxel alone. ${ }^{37}$ To the best of our knowledge, other cancer trials targeting the prolactin/prolactin receptor axis, in breast cancer or even other types of cancer, have not been published.

According to Carver et $a l^{33}$ the relatively restricted distribution of prolactin receptor as well as the limited disturbance in phenotype of the prolactin receptor-/ - transgenic mice apart from morphological changes occurring within the mammary gland suggests that therapeutics directed toward prolactin/prolactin receptor should be well tolerated, increasing its appeal. According to our data, the widespread expression of prolactin receptor in primary tissues as well as in regional and distant metastatic sites of colorectal cancer makes this type of cancer an ideal candidate for prolactin/prolactin receptor-targeted therapy. Moreover, the concordant expression profiles of primary tumors and corresponding metastases facilitate the promise of individualized treatment for metastatic disease, as tailored medicine can be accomplished without taking additional biopsies from metastatic deposits.

In conclusion, prolactin receptor is widely expressed in colorectal cancer. High concordance rates between primary tumor and metastatic tissues make this protein a promising target in patients with advanced disease. Moreover, prolactin receptor expression may be an additional prognostic variable, particularly in high-grade and mucinous cancers.

\section{Acknowledgement}

We are grateful to Mrs M Schuller, Mrs J Strutz, and Mrs A Kaps for excellent technical assistance.

\section{Disclosure/conflict of interest}

The authors declare no conflict of interest.

\section{References}

1 Boyle P, Levin B. World Health Organization. World Cancer Report 2008. IARC Press: Lyon, 2008, pp 374-378.

2 Jemal A, Siegel R, Ward E, et al. Cancer statistics, 2008. CA Cancer J Clin 2008;58:71-96.

3 Hampton T. New therapies for GI cancers fall short. JAMA 2009;302:373-374.

4 Moertel CG, Fleming TR, MacDonald JS, et al. Levamisole and fluorouracil for adjuvant therapy of resected colon carcinoma. N Engl J Med 1990;322: 352-358.

5 MacFarlane JK, Ryall RD, Heald RJ. Mesorectal excision for rectal cancer. Lancet 1993;341:457-460.

6 Sauer R, Becker H, Hohenberger W, et al. Preoperative versus postoperative chemoradiotherapy for rectal cancer. N Engl J Med 2004;351:1731-1740.

7 Chau I, Cunningham D. Treatment in advanced colorectal cancer: what, when and how? Br J Cancer 2009;100:1704-10719.

8 Ciardiello F, Tortora G. EGFR antagonists in cancer treatment. N Engl J Med 2008;358:1160-1174.

9 Allegra CJ, Yothers G, O’Connell MJ, et al. Initial safety report of NSABP C-08: A randomized phase III study of modified FOLFOX6 with or without bevacizumab for the adjuvant treatment of patients with stage II or III colon cancer. J Clin Oncol 2009;27:3385-3390.

10 Nagano M, Chastre E, Choquet A, et al. Expression of prolactin and growth hormone receptor genes and their isoforms in the gastrointestinal tract. Am J Physiol 1995;268:431-442.

11 Bole-Feysot C, Goffin V, Edery M, et al. Prolactin (PRL) and its receptor: actions, signal transduction pathways 
and phenotypes observed in PRL receptor knockout mice. Endocr Rev 1998;19:225-268.

12 Clevenger CV, Zheng J, Jablonski EM, et al. From bench to bedside: future potential for the translation of prolactin inhibitors as breast cancer therapeutics. J Mammary Gland Biol Neoplasia 2008;13:147-156.

13 Reynolds C, Montone KT, Powell CM, et al. Expression of prolactin and its receptor in human breast carcinoma. Endocrinology 1997;138:5555-5560.

14 Vonderhaar BK. Prolactin involvement in breast cancer. Endocr Relat Cancer 1999;6:389-404.

15 Tallet E, Rouet V, Jomain JB, et al. Rational design of competitive prolactin/growth hormone receptor antagonists. J Mammary Gland Biol Neoplasia 2008; 13:105-117.

16 Walker AM. Therapeutic potential of S179D prolactinfrom prostate cancer to angioproliferative disorders: the first selective prolactin receptor modulator. Expert Opin Investig Drugs 2006;15:1257-1267.

17 Goffin V, Bernichtein S, Touraine P, et al. Development and potential clinical uses of human prolactin receptor antagonists. Endocr Rev 2005;26:400-422.

18 Bhatavdekar J, Patel D, Ghosh N, et al. Interrelationship of prolactin and its receptor in carcinoma of colon and rectum: a preliminary report. J Surg Oncol 1994;55:246-249.

19 Bhatavdekar JM, Patel DD, Chikhlikar PR, et al. Ectopic production of prolactin by colorectal adenocarcinoma. Dis Colon Rectum 2001;44:119-127.

20 Otte JM, Otte C, Beckedorf S, et al. Expression of functional prolactin and its receptor in colorectal cancer. Int J Coloretal Dis 2003;18:86-94.

21 Sobin LH, Wittekind C, (eds) TNM Classification of Malignant Tumors, 6th edn. Wiley-Liss: New York, 2002.

22 Hamilton SR, Vogelstein B, Kudo S, et al. Carcinoma of the colon and rectum In: Hamilton SR, Aaltonen LA (eds). World Health Organization Classification of Tumours. Pathology and Genetics. Tumours of the Digestive System. IARC Press: Lyon, 2000, pp 105-119.

23 Kononen J, Bubendorf L, Kallioniemi A, et al. Tissue microarrays for high-throughput molecular profiling of tumor specimens. Nat Med 1998;4:844-847.

24 Kersten HM, Robben JC, Poddinghe PJ, et al. AgarCyto: a novel cell processing method for multiple molecular diagnostic analyses of uterine cervix. J Histochem Cytochem 2000;48:709-718.
25 Ben-Jonathan N, Mershon JL, Allen DL, et al. Extrapituitary prolactin: distribution, regulation, functions, and clinical aspects. Endocr Rev 1996;17: 639-669.

26 De Vries JE, Dinjens WN, De Bruyne GK, et al. In vivo and in vitro invasion in relation to phenotypic characteristics of human colorectal carcinoma cells. Br J Cancer 1995;71:271-277.

27 Baert D, Matthys C, Gillardin JP, et al. Prolactin and colorectal cancer: is there a connection? Acta Gastroenterol Belg 1998;61:407-409.

28 Carlson HE, Zarrabi MH, Lyubsky SL. Lack of association between hyperprolactinemia and colon carcinoma. Cancer Invest 2000;18:130-134.

29 Wood AJ, Thomas CM, Baumforth KRN, et al. Absence of prolactin gene expression in colorectal cancer. J Clin Pathol 1999;52:135-139.

30 Bhatavdekar JM, Patel DD, Chikhlikar PR, et al. Molecular markers are predictors of recurrence and survival in patients with Dukes B and Dukes C colorectal adenocarcinoma. Dis Colon Rectum 2001;44:523-533.

31 Ilan Y, Sibirsky O, Livni N, et al. Plasma and tumor prolactin in colorectal cancer patients. Dig Dis Sci 1995;40:2010-2015.

32 Indinnimeo M, Cicchini C, Memeo L, et al. Plasma and tissue prolactin detection in colon carcinoma. Oncol Rep 2001;8:1351-1353.

33 Carver KC, Arendt LM, Schuler LA. Complex prolactin crosstalk in breast cancer: new therapeutic implications. Mol Cell Endocrinol 2009;307:1-7.

34 Bernichtein S, Kayser C, Dillner K, et al. Development of pure prolactin receptor antagonists. J Biol Chem 2003;278:35988-35999.

35 Beck MT, Chen NY, Franek KJ, et al. Prolactin antagonist-endostatin fusion protein as a targeted dual-functional therapeutic agent for breast cancer. Cancer Res 2003;63:3598-3604.

36 Langenheim JF, Chen WY. Development of a prolactin receptor-targeting fusion toxin using a prolactin antagonist and a recombinant form of Pseudomonas exotoxin A. Breast Cancer Res Treat 2005;90: 281-293.

37 Frontini L, Lissoni P, Vaghi M, et al. Enhancement of the efficacy of weekly low-dose taxotere by the long acting anti-prolactinemic drug cabergoline in pretreated metastatic breast cancer. Anticancer Res 2004;24:4223-4226. 